\title{
PRÁTICAS E PERCEPÇÕES DA DOAÇÃO ENTRE A POPULAÇÃO DE ALTA RENDA NO BRASIL
}

\author{
Fernando do Amaral Nogueira \\ Alexandre Abdal \\ Pedro Henrique Campos
}

\begin{abstract}
// resumo
O presente ensaio apresenta e discute alguns dos resultados mais significativos da Pesquisa Comportamental sobre Doadores de Alta Renda (PCDAR), realizada pelo Centro de Estudos em Administração e Governo (CEAPG) da Fundação Getulio Vargas (FGV) e a Conectas Direitos Humanos, bem como desdobramentos em termos de recomendações de ações para o fortalecimento do ecossistema de doação para as organizações do campo dos direitos humanos. A PCDAR, realizada em 2018, foi uma pesquisa exploratória multimétodos sobre o perfil sociodemográfico e comportamental da população de alta renda. Os resultados foram agrupados em cinco eixos: especificidades sociodemográficas da população de alta renda; hábitos diversificados e enraizados de doação; valores doados, flexibilidade e conveniência; confiança; e percepções sobre direitos humanos. As recomendações implicam quatro conjuntos de ações: conscientização e disputa de significados; contato e comunicação; demonstração de impacto; e flexibilização da doação.
\end{abstract}

palavras-chave: cultura de doação | doação | doadores de alta renda | organizações de direitos humanos. 


\section{artigos GIFE}

\section{OS ARTIGOS GIFE}

A série Artigos GIFE publica reflexões e análises de pesquisadores brasileiros de diferentes áreas do saber com o objetivo de estimular, ampliar e disseminar a produção de conhecimento qualificado sobre o campo da filantropia, do investimento social privado e da sociedade civil no Brasil.

A partir da premissa de que a produção de conhecimento sobre esses temas tem um papel fundamental na expansão, diversificação e qualificação da ação pública pela sociedade, a iniciativa também pretende contribuir para ampliar as conexões entre o setor, as universidades e os centros de pesquisa, promovendo e apoiando o envolvimento de novos atores com a temática e a circulação ampliada de ideias em torno dela.

Este texto integra a segunda edição dos Artigos GIFE, que propõe a publicação mensal de artigos selecionados por meio de chamada pública e convite a autores especialistas em temáticas específicas e relevantes para o setor, buscando apoiar e fomentar a produção de conhecimento sobre o investimento social no Brasil.

O Grupo de Institutos Fundações e Empresas (GIFE) é uma organização sem fins lucrativos que reúne associados de origem empresarial, familiar ou independente que investem em projetos de interesse público. Criado em 1989 como grupo de troca e colaboração e institucionalizado em 1995 por 25 organizações, tornou-se referência no campo da filantropia e do investimento social privado no Brasil.

Nesses mais de 20 anos de atuação, tem contribuído para o fortalecimento de práticas e ações a serviço do bem comum no país, trabalhando para expandir, qualificar e fortalecer o investimento social privado, diversificar e ampliar atores e recursos, criando referências e estimulando boas práticas de gestão, bem como articulando o setor com a sociedade e a agenda pública. Atualmente, o GIFE reúne mais de 150 associados que, somados, aportam mais de $\mathrm{R} \$ 3$ bilhões por ano em projetos próprios e no apoio a projetos de terceiros. 
A primeira história é sempre sobre um nascimento. Se já se é mãe, é sobre o nascimento dos filhos. Toda mulher conta o nascimento do próprio filho ou filha dezenas, centenas, milhares de vezes. E todas as vezes conta-o como se tivesse acabado de acontecer. Todas as sensações, até as piores, estão frescas como se fossem recém-vividas.

Igiaba Scego, in Minha casa é onde estou

\section{INTRODUÇÃO ${ }^{1}$}

Este ensaio se propõe a apresentar e discutir dados, análises e achados resultantes da Pesquisa sobre o Comportamento de Doadores de Alta Renda (PCDAR) no Brasil (ABDAL et al., 2019). Nosso objetivo principal é entender quem é o potencial doador de alta renda e qual a sua disposição a doar a organizações do campo de direitos humanos. A PCDAR foi realizada por pesquisadores do Centro de Estudos em Administração Pública e Governo (CEAPG) da Escola de Administração de Empresas da Fundação Getulio Vargas (FGV EAESP), em parceria com a Conectas Direitos Humanos, e contou com o financiamento do Fundo Bis e do GVPesquisa.

A PCDAR teve, como contexto, o desafio de promover o fortalecimento da cultura de doação e solidariedade no país, em um momento de ambiguidades entre o crescimento e a profissionalização das organizações da sociedade civil e a realidade de crise social, polarização política e estagnação econômica atuais. São duas as principais consequências dessa dualidade: o desafio de sustentabilidade institucional e financeira e as crescentes restrições às liberdades necessárias para a sua atuação enquanto relevante ator político. Destacamos que essas consequências são especialmente sentidas por organizações que atuam no campo da defesa de direitos, como apontado por Mendonça, Alves e Nogueira (2016).

Oferecendo uma das muitas possíveis respostas ao cenário acima, na PCDAR buscamos a produção de informação rigorosa sobre um público pouco estudado, os potenciais doadores de alta renda, e utilizamos diferentes métodos e técnicas de pesquisa, como detalhamos a seguir. Com isso, almejamos trazer um retrato mais completo sobre o perfil desse público e contribuições tanto acadêmicas, com novos dados primários, análises e novas perguntas para futuras pesquisas, quanto para a prática dos gestores de organizações da sociedade civil em geral e, em específico, para os do campo de direitos humanos.

É importante ressaltar que este ensaio é um recorte específico da PCDAR. Todos os resultados da pesquisa principal estão disponíveis no $s_{i t e}^{2}$, onde se encontram o relatório completo e os dados coletados e organizados para serem baixados (ABDAL et al., 2019), permitindo e incentivando novas análises e estudos por outros pesquisadores interessados.

Depois desta introdução, apresentamos uma breve seção metodológica e de definições usadas na PCDAR. Em seguida, trazemos cinco dos principais achados da pesquisa. Finalmente, fazemos algumas recomendações práticas para organizações da sociedade civil, em destaque aquelas do campo de direitos humanos.

1 Os autores agradecem toda a equipe de pesquisa, a equipe do CEAPG, o GVPesquisa e o Fundo BIS pelo financiamento e, em especial, a equipe da Conectas (Juana, Amanda, Teresa e Leonardo).

2 Disponível em: https://doadoresaltarenda.conectas.org/. 


\section{DEFINIÇÕES OPERACIONAIS E TRAJETÓRIA DA PCDAR}

A PCDAR começou com a decisão de estudar os potenciais doadores de alta renda como forma de responder a uma lacuna na literatura acadêmica e profissional brasileira. Ainda que venha crescendo a produção de dados e pesquisas sobre o comportamento do doador nacional (BAILEY, 1999; MENDONÇA, ALVES e NOGUEIRA, 2013; IDIS, 2015), o foco costuma ser o doador mediano ou típico: pessoas físicas que doam cerca de 30 reais por mês. Assim, constatamos que pouco se discute sobre estratégias de captação e fidelização de públicos com maior poder aquisitivo (IDIS, 2015).

Nosso desafio seguinte foi adotar uma definição precisa para o doador que queríamos estudar. Uma revisão da literatura internacional traz dois possíveis conceitos: o de doadores médios (middle-donors) e o de indivíduos de alto poder aquisitivo (high-net-worth individuals). No entanto, encontramos problemas ao adaptar tais definições à realidade brasileira. Assim, optamos por usar o conceito de potenciais doadores de alta renda, definidos na prática como profissionais em meio de carreira e com altos salários, cuja renda média mensal é igual ou superior a 30 mil reais.

Tendo em vista esse cenário desafiador com relação à definição do público objeto do estudo, desenhamos uma estratégia de pesquisa que pudesse identificar, de um lado, quem são e o que fazem os doadores de alta renda e, de outro, quais são seus valores e suas percepções. Isso implicou a combinação de três modelos distintos de coleta, produção e organização de informações: (i) a análise de bancos de dados secundários e públicos ${ }^{3}$; (ii) a condução de um grupo focal ${ }^{4}$; e (iii) a elaboração de um survey ${ }^{5}$. O processo foi marcado por uma estratégia multimétodos e exploratória de pesquisa, que combina uma dimensão macro (aspectos demográficos e ocupacionais) com uma dimensão micro (percepções e motivação).

Destacamos dois pontos fortes associados a uma estratégia como essa. O primeiro é que os achados de uma fase orientam o prosseguimento da pesquisa e das demais fases, ao mesmo tempo em que produzem resultados parciais substantivos. Tal como a discussão teórica sobre a definição de doadores de alta renda informa o recorte de remuneração, as informações acerca do perfil ocupacional da população de alta renda orientam a seleção de indivíduos para o grupo focal, e as respostas obtidas no focal auxiliam na elaboração do survey. A segunda vantagem refere-se ao fato de que a utilização simultânea de técnicas distintas de pesquisa, cada qual com virtudes e desafios próprios, possibilita a obtenção de informação complementar e ilumina aspectos diferentes do fenômeno de interesse.

Todas as coletas e análises ocorreram ao longo de 2018 e os seus procedimentos detalhados se encontram descritos na PCDAR.

\section{CINCO ACHADOS RELEVANTES DA PCDAR}

Nesta seção, trazemos à tona e discutimos alguns dos achados da PCDAR que julgamos mais significativos, embora eles não esgotem todo o rol de resultados da pesquisa. Agrupamos os resultados em cinco ideias: (i) especificidades sociodemográficas da população de alta renda; (ii), hábitos diversificados e enraizados de doação; (iii) valores, flexibilidade e conveniência; (iv) confiança como fundamento da doação; e (v) percepções a respeito da temática dos direitos humanos.

3 As fontes utilizadas foram a Relação Anual de Informações Sociais (Rais), do extinto Ministério do Trabalho e Emprego (MTE) e Grandes Números das Declarações do Imposto de Renda de Pessoa Física (GN-DIRPF).

4. Um grupo focal é uma técnica qualitativa de pesquisa cuja evidência, de tipo discursiva, é gerada na e pela conversa mediada entre os participantes (ALMEIDA, 2016). A PCDAR realizou um grupo focal, com seis participantes controlados por sexo, cor ou raça, idade e grupo ocupacional.

5 Um survey (ou pesquisa de opinião) é uma técnica quantitativa de pesquisa que envolve interação controlada entre pesquisador e respondente mediante questionário estruturado e padronizado (BABBIE, 2003). A PCDAR realizou um survey com 348 doadores e não doadores de alta renda. A sua amostra foi não probabilística, não permitindo, portanto, generalizações estatísticas. A principal justificativa para essa estratégia amostral refere-se à indisponibilidade de informações precisas e dados cadastrais a respeito dessa população. Contudo, como nos mostra Howard Becker (2007), amostras não probabilísticas são de grande serventia para análises exploratórias de populações que se conhece pouco e para a captação da maior variabilidade possível de um dado fenômeno social. 
Cada ponto a seguir é iniciado com uma breve citação do relatório descritivo do grupo focal da PCDAR (ABDAL et al., 2018), a fim de ilustrar de forma mais qualitativa a ideia desenvolvida.

\subsection{Doadores de alta renda como um público específico ${ }^{6}$}

M., 30 anos, branca, Direito pela USP, diplomata há cinco anos, chefe da administração consular em [...]. P., 45 anos, formação em direito com trajetória que se inicia na academia e chega ao mercado financeiro como superintendente do BNDES e, depois, como gestor de fundos de investimentos (private equity e investimentos em startups), hoje tem a sua própria empresa. (ABDAL et al., 2018, p. 1).

Os doadores de alta renda compõem um segmento diminuto e bastante específico da população brasileira. Embora essa ideia seja intuitiva, destacamos as particularidades mais relevantes desse segmento populacional em termos sociodemográfico e ocupacional.

A depender dos parâmetros de cálculo e considerando a definição operacional de 30 mil reais mensais de todas as fontes, os doadores de alta renda integram um conjunto populacional que varia entre $0,25 \% \mathrm{e}$ pouco menos de $1,00 \%$ da população brasileira em idade ativa, cerca de um milhão de pessoas. Ou $0,20 \%$ dos ocupados em relações formais de trabalho, aproximadamente 130 mil indivíduos.

Em termos sociodemográficos, esse é um segmento da população predominantemente masculino, de meia idade (40 a 64 anos), branco, residente no Sudeste e Centro-Oeste, sobretudo Brasília, e mais escolarizado. Do ponto de vista ocupacional, se encontra relativamente mais empregado no setor privado, em posições de diretoria e gerência, e é acompanhada pelo setor público, com os magistrados, não havendo profissão predominante dentre o setor de profissionais liberais. A Figura 1 ilustra essa comparação entre público e população.

\section{Figura 1 - Comparação de aspectos sociodemográficos entre população de alta renda e total da população na Rais, Brasil, 2016}

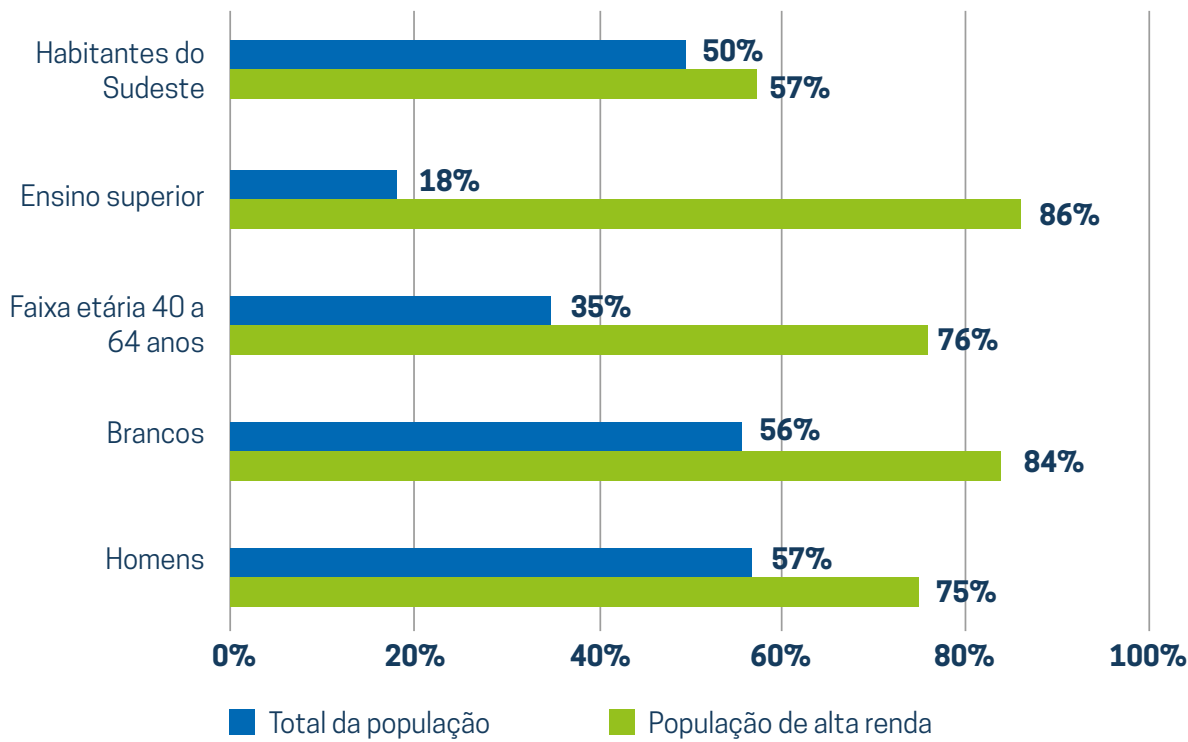

Fonte: Rais/MTE, 2016. Elaboração própria.

6 Todos os dados apresentados nesta subseção têm como fonte o GN-DIRPF de 2018 ou a Rais de 2016. 


\subsection{Hábitos diversificados e enraizados de doação}

Alguma hesitação depois, S. tomou a palavra e disse achar que a solidariedade é uma coisa ampla [...] e que é doadora da Fundação Estudar, para a qual contribui com certa regularidade para o financiamento de bolsas de estudos. Também disse ajudar com os estudos de pessoas próximas e conhecidas dela, como o filho de uma prima a fazer 'Kumon'. [...] D. foi o próximo a tomar a palavra e também apresentou diferentes práticas de solidariedade, desde contribuições sistemáticas em dinheiro à organização Cadeidoscópio [...] [e] ao Médico Sem Fronteiras [...] passando por investimento anjo [...] e coaching pro bono com refugiados [...] até chegar em ajudas - doações mais pontuais para conhecidos e/ou filhos de conhecidos, como funcionários do café de sua mulher”. (ABDAL et al., 2018, p. 2).

Impera um senso comum segundo o qual não haveria cultura de doação no Brasil. Ou, pelo menos, ela seria insuficiente e bastante inferior à dos países desenvolvidos, particularmente de origem anglo-saxã. Resultados como o do World Giving Index (CAF, 2018), em que o Brasil figura na $122^{a}$ posição de um total de 146 países, reforçaria a percepção do senso comum.

Argumentamos o inverso, entretanto, e destacamos que a evidência disponível sugere outra interpretação. A saber, há sim uma cultura de doação no Brasil com características próprias e ela interage com a nossa formação enquanto sociedade nacional. Essa nossa cultura de doação pode estar mais ou menos distante do que as organizações que dependem de doações ou os captadores de recursos gostariam, mas, como argumentamos, ela existe.

De acordo com a Pesquisa Doação Brasil, em 2015, 77\% dos brasileiros realizou algum tipo de doação, seja em dinheiro, bens ou tempo. E, mais importante, $46 \%$ dos brasileiros efetivou doação institucional em dinheiro para alguma organização (IDIS, 2016). Já em nossa pesquisa, com um público significativamente mais restrito, os resultados são convergentes: também $77 \%$ dos respondentes de alta renda realizou alguma modalidade de doação em 2017 e 59\% deles fez alguma doação em dinheiro para organização ou entidade social.

\section{Tabela 1 - Práticas de solidariedade e doação, Brasil, população de alta renda, 2018}

\begin{tabular}{|c|c|c|}
\hline & N. & $\%$ \\
\hline Doação de dinheiro para organizações ou entidades sociais & 206 & 76,9 \\
\hline Doação de bens ou serviços para organizações/entidades sociais & 163 & 60,8 \\
\hline Doação em dinheiro diretamente para pessoas conhecidas ou próximas & 159 & 59,3 \\
\hline Esmola ou doação em dinheiro diretamente para desconhecidos & 115 & 42,9 \\
\hline $\begin{array}{l}\text { Doação em dinheiro e incentivada para, por exemplo, projetos culturais ou esportivos e/ou para Fundos da } \\
\text { Criança e do Adolescente ou do Idoso }\end{array}$ & 114 & 42,5 \\
\hline Doação em tempo / horas voluntárias para organizações / entidades sociais & 96 & 35,8 \\
\hline Doação não monetária (tempo, bens ou serviços) diretamente para pessoas conhecidas ou próximas & 84 & 31,3 \\
\hline Doação de qualquer tipo para campanhas de ajuda a desabrigados ou calamidades & 78 & 29,1 \\
\hline Dízimo ou doação de qualquer tipo para a Igreja & 73 & 27,2 \\
\hline Doação de sangue e/ou órgãos & 60 & 22,4 \\
\hline Doação não monetária (tempo, bens ou serviços) diretamente para desconhecidos & 40 & 14,9 \\
\hline Total 1 (indivíduos) & 268 & 100,0 \\
\hline Total 2 (menções / respostas) & 1.188 & 428,4 \\
\hline
\end{tabular}

Fonte: Adaptado de ABDAL et al., 2019, p. 29 
A Tabela 1, assim como a evidência extraída do grupo focal, ajuda a caracterizar as linhas gerais da cultura de doação entre a população de alta renda no Brasil. Ela se caracteriza pela interação entre duas grandes tendências, aparentemente contraditórias, mas coerentemente articuladas do ponto de vista do doador de alta renda. Caracterizamos esse inusitado encontro como um duplo padrão complementar, que combina um tipo de doação impessoal-formal e mais estruturado, cujo exemplo mais bem acabado é a doação em dinheiro, previamente planejada, para uma organização ou entidade social; com outro tipo de doação pessoal-informal, menos ou nada estruturada, cujo exemplo que trazemos é a doação de um tratamento de saúde ou um curso, qualquer que seja, para algum empregado doméstico ou familiar do doador.

Enquanto o primeiro tipo de doação está inserido no universo dos desejos das organizações e dos captadores de recursos, o segundo tipo de doação conversa com a tradição da nossa formação enquanto sociedade nacional - e, forçando nas tintas, se o primeiro tipo aponta para um futuro moderno, o segundo tipo não nos deixa esquecer nossos arcaísmos sociais. Destacamos, especificamente, as aproximações possíveis desse padrão pessoal e familiar de doação com a predominância da unidade familiar na formação nacional brasileira (PRADO Jr., 1969; VIANNA, 1987; FREYRE, 2006), incrustrado, por exemplo, na noção de cordialidade de Sérgio Buarque de Holanda (1963), para quem a cordialidade implica uma modalidade flexível de dominação, baseada nos afetos e emoções, mas, ao mesmo tempo, autoritária e hierárquica, intensiva na demarcação das diferenças e denotando uma estrutura social dura e inflexível (DAMATTA, 1997).

Ao fim e ao cabo, o que temos nesse e por esse duplo padrão é um conjunto heterogêneo, diversificado e enraizado de práticas de doação. Se o peso do passado permanece grande, destacamos que há espaço para as organizações e os captadores trabalharem ainda mais a diversificação das práticas de doação, a formalização e a estruturação de práticas informais e pouco estruturadas. Por exemplo, fomentando a quem já doa cursos educacionais para pessoas próximas doar, também, para fundos de bolsa.

\subsection{Valores doados, flexibilidade e conveniência}

G. buscou justificar o fato de não fazer mais atividades com a correria da vida, que não consegue pensar muito nisso [doações], mas que em sua agência as coisas sempre chegam. E que faria mais doações se as coisas fossem mais convenientes. (ABDAL et al., 2018, p. 4).

Um desdobramento interessante da discussão anterior, quando se argumentava que a cultura de doação brasileira - ou, pelo menos, de suas elites econômicas - é caracterizada por um duplo padrão, é a observação dos valores doados dentro daquilo que chamamos de padrão impessoal-formal e mais estruturado de doação. Isso porque é dentro desse padrão que as doações em dinheiro para organizações ou entidades sociais acontecem.

A observação da Tabela 2 e da Tabela 3 sugere doações médias daqueles que declaram doar não desprezíveis (aproximadamente 3.500,00 reais por organização/ano, considerando todas as doações), principalmente quando comparada com a média de doação institucional da população brasileira: 240,00 reais por organização/ano (IDIS, 2016). Contudo, um olhar mais atento revela importantes nuances encobertas pelas médias. 
Tabela 2 - Estatística descritiva para os valores anuais médios de doação para organizações ou entidades sociais, Brasil, população de alta renda, 2018

\begin{tabular}{|c|c|c|c|c|}
\hline & Organização 1 & Organização 2 & Organização 3 & Todas as organizações \\
\hline Média & $4.931,0$ & $2.416,7$ & $2.054,4$ & $3.544,7$ \\
\hline Mediana & $1.000,0$ & 525,0 & 500,0 & 600,0 \\
\hline Desvio Padrão & $17.834,2$ & $9.059,4$ & $4.459,4$ & $13.570,5$ \\
\hline Máximo & $165.000,0$ & $80.000,0$ & $30.000,0$ & $165.000,0$ \\
\hline Mínimo & 20,0 & 30,0 & 30,0 & 20,0 \\
\hline N & 241,0 & 172,0 & 94,0 & 507,0 \\
\hline
\end{tabular}

Fonte: Adaptado de ABDAL et al., 2019, p. 32.

Em primeiro lugar, chamamos a atenção para as significativas diferenças entre médias e medianas, de quatro a cinco vezes, sugerindo uma grande dispersão das doações entre poucas doações de valor alto e muitas de valor baixo. Outra forma de observar essa tendência vem dos valores máximos e mínimos da doação, os quais variam de dezenas para dezenas de milhares de reais, além da existência de desvios padrões altos. Por que essa evidência é relevante? Porque junto com a informação da Tabela 3, de que dois terços dos doadores de alta renda comprometem menos de $1 \%$ de sua renda mensal com doação ${ }^{7}$, emerge a percepção de que há importante espaço para a ampliação dos valores doados.

Tabela 3 - Proporção da renda dispendida com doações, Brasil, população de alta renda, 2018

\begin{tabular}{|c|c|c|}
\hline & N. & $\%$ \\
\hline Até $0,1 \%$ & 61 & 17,5 \\
\hline $0,1 \%$ até $0,5 \%$ & 94 & 27,0 \\
\hline $0,5 \%$ a $1 \%$ & 71 & 20,4 \\
\hline $1 \%$ a $2 \%$ & 40 & 11,5 \\
\hline $2 \%$ a $5 \%$ & 39 & 11,2 \\
\hline Mais de $5 \%$ & 18 & 5,2 \\
\hline Sem resposta & 25 & 7,2 \\
\hline Total & 348 & 100,0 \\
\hline
\end{tabular}

Fonte: Adaptado de ABDAL et al., 2019, p. 33.

Em segundo lugar, apresentamos informação complementar da PCDAR, toda no sentido de corroborar a percepção de existência de espaço para a ampliação dos valores doados, por exemplo, associado a ações por parte das organizações e captadores no sentido de incentivar práticas de planejamento anual de doação, flexibilizar meios de pagamento da doação e tornar a temática da doação mais presente no cotidiano das pessoas, seja em seus círculos familiares, de amizade ou profissionais. Nos termos dos participantes do grupo focal, tornar a doação mais conveniente. Vamos aos dados:

- $52 \%$ dos doadores-respondentes de alta renda não têm planejamento anual de sua doação;

- os meios de pagamento preferidos de doação (boleto, cartão de crédito e transferência

7 Valor tido como boa prática em comportamento filantrópico por profissionais do campo. Como exemplo, ver movimentos como o https://pledge1 percent.org/. 
bancária, nessa ordem) não são os meios mais utilizados (dinheiro, transferência bancária e boleto, nessa ordem); e

- $78 \%$ dos doadores-respondentes de alta renda disseram não ser comum e nem muito comum a conversa, com quem quer que seja, sobre doação em seu cotidiano.

\subsection{Confiança como fundamento da doação}

D. lembrou que sempre doa para uma amiga que é do Médicos Sem Fronteira e que trabalha por dois meses na Nigéria todos os anos. Disse que conheceu a organização por meio dela e que essa conexão com a amiga é fundamental para que ele faça a doação. (ABDAL et al., 2018, p. 11).

Um ponto convergente da literatura sobre doação, o senso comum e outras pesquisas existentes, como a já citada Pesquisa Doação Brasil (IDIS, 2016), é a íntima e positiva relação entre doação e confiança. $\mathrm{Na}$ PCDAR isso não apareceu de forma diversa e, considerando o grupo focal e o survey, podemos afirmar com segurança que os doadores de alta renda concebem a confiança como substrato da doação. Por exemplo:

- $90 \%$ dos doadores-respondentes de alta renda disseram que "perder a confiança” é o principal motivo que os levaria a interromper a doação;

- $60 \%$ dos não doadores-respondentes declararam que a ausência de confiança naquele que pede ser o principal motivo para não doar; e

- $98 \%$ de todos os respondentes afirmaram a confiança ser importante ou muito importante para a doação.

Agora, o que exatamente significa confiança para a população de alta renda? Como construíla e como mantê-la? Nossos resultados ajudam a tatear respostas. Destacamos que a categoria confiança pode ser dividida em dois momentos: construção e manutenção. E que os fatores que subsidiam o processo de construção da confiança são diferentes dos fatores que subsidiam sua manutenção.

A construção da confiança é um processo, não necessariamente linear ou progressivo, que combina elementos impessoais e de baixa intensidade, associados ao conhecimento da organização, com elementos pessoais associados à confiança propriamente. Pelos nossos resultados, a população de alta renda prefere e está mais aberta para receber informações a respeito das organizações por meios derivados de estratégias de comunicação não apelativas e de baixa intensidade, como correspondência (eletrônica ou não), mídia e redes sociais. A abordagem direta, seja na rua, telefone ou porta de casa, é majoritariamente execrada.

Conhecer minimamente uma organização não significa confiar nela a ponto de doar. Nesse momento entra em cena a relevância dos elementos pessoais na construção da confiança, com enorme destaque para a indicação de familiares próximos, como cônjuges ou filhos. Familiares menos próximos, amigos e colegas de trabalho também foram citados como importantes para a construção da confiança. Interessante notar como o apoio de celebridades não apareceu como fator de relevância para a construção da confiança pela população de alta renda.

Já a manutenção da confiança e, portanto, a manutenção das condições da perenidade e sistematicidade da doação, tem a ver com elementos associados ao desempenho, transparência e estratégia de comunicação das organizações. Agrupamos tais elementos em quatro dimensões, apontando em parênteses qual o percentual de respondentes que os $\operatorname{citam}^{8}$, como segue. 
- Transparência (56\%). Implica administração adequada dos recursos, prestação de contas e clareza de objetivos.

- Impacto (46\%). Remete à capacidade das organizações em chegar nas pessoas, entregar os seus produtos ou serviços e atingir os seus objetivos.

- Verificação externa e demonstração dos resultados (26\%). Engloba desde a verificação das atividades da organização por atores independentes e auditorias periódicas até a capacidade da organização em demonstrar resultados e manter reputação.

- Uso republicano dos recursos (17\%). Sinaliza a ausência do envolvimento da organização em corrupção ou desvios e a não utilização da organização para enriquecimento de seus membros.

\subsection{Desconhecimento e resistência inicial à temática dos direitos humanos}

A. questionou sobre temas de direitos humanos. F. disse que é um tema supervago e que, num país como o nosso [Brasil], precisamos descer no detalhe para traduzir o que cabe nisso. [...]. G. disse que acha o tema distorcido: diz que no Brasil tudo é distorcido, e que os direitos humanos aparecem para defender quem não precisa [...]. P. lembrou que direitos humanos já foram abordados na conversa, com o trabalho que D. mencionou [...] e que é possível fazer uma discussão mais ampla, associada à dimensão de acesso a condições mínimas de qualquer ser humano para viver e ter oportunidades iguais. (ABDAL et al., 2018, p. 9).

Muitas são as causas prezadas pelos potenciais doadores de alta renda. Entre as principais, temos criança e adolescente, saúde, educação, fome, pobreza e idosos. É forçoso reconhecer que direitos humanos praticamente não aparece, tendo sido diretamente citada apenas por três respondentes do survey. Quando foram perguntados especificamente sobre temas específicos do campo, os que mais sensibilizam são população em situação de rua, segurança, mulheres e desrespeito de direitos por empresas. Na outra ponta, encontram-se temáticas ligadas a grupos minoritários, como ações afirmativas, indígenas e quilombolas e população LGBT+.

Uma hipótese plausível que os dados sugerem é que o termo direitos humanos não faz parte do universo simbólico do público em seu cotidiano. Por esse misto de desconhecimento e resistência, não é de surpreender que mais da metade dos respondentes (56\%) nunca doou para organizações de direitos humanos.

Restam assim dois grupos, cada um de tamanho equivalente (perto de $20 \%$ ): os que já doaram ou doam de forma esporádica ou regular e os que nunca doaram nem pretendem doar. Esse quadro sugere a necessidade de planejar diferentes estratégias de comunicação e captação de recursos voltadas a cada um desses públicos, bem como sinaliza o potencial dos doadores de alta renda: quatro entre cinco mostram-se dispostos a doarem para organizações do campo.

\section{AÇÕES PARA O FORTALECIMENTO DO ECOSSISTEMA DE DOAÇÕES PARA O CAMPO DOS DIREITOS HUMANOS}

Como parte final deste artigo, destacamos a seguir algumas considerações para contribuição direta à prática das organizações, em geral, e do campo de direitos humanos, em particular. Acreditamos que estas reflexões podem ajudar em seu fortalecimento e desenvolvimento institucional, tanto pelo potencial maior fluxo de recursos quanto pelo desenvolvimento de capacidade organizacional que pode ser aplicada a outros públicos e fontes. 


\subsection{Conscientização e disputa de significados}

Como visto, há grande desconhecimento sobre o tema de direitos humanos, tanto na população em geral como no público tratado pela PCDAR. Há também bastante incompreensão, tanto sobre o conceito em si como sobre a multiplicidade de temas específicos que compõem o campo, resultando em uma visão incompleta ou fragmentada. Somam-se a isso questionamentos de caráter ideológico, especialmente com causas de baixo apelo midiático (como temas ligados à situação carcerária).

Não foi objetivo da pesquisa explicar o motivo dessa situação, mas é plausível lançar a hipótese de que resulta, em parte, da cultura organizacional de boa parte das organizações do campo de captar recursos e prestar contas principalmente com doadores internacionais já sensíveis e conscientes da relevância do tema (como discutido em MENDONÇA, NOGUEIRA e ALVES, 2016).

Como potencial ação imediata, campanhas institucionais que articulem ideias e conceitos de direitos humanos, noção de dignidade humana e as próprias atividades desenvolvidas

Nesse sentido, investir mais atenção e recursos à comunicação de forma ampla torna-se fundamental. Isso inclui ter como focos de comunicação a própria organização e suas atividades, temas específicos do campo (alguns, mais palatáveis do que outros, podem servir de porta de entrada) e também a defesa da área como um todo. Uma ideia que pode facilitar a apresentação de tantos e tão complexos conceitos é a imagem da garantia de dignidade da pessoa, que parece ter boa receptividade por parte do público da pesquisa.

Assim, começam a se desenhar estratégias de curto e longo prazo. Como potencial ação imediata, sugerimos começar por campanhas institucionais que articulem ideias e conceitos de direitos humanos, noção de dignidade humana e as próprias atividades desenvolvidas pela organização. Já a médio e longo prazo, é difícil imaginar avanços sem que haja esforços consideráveis de cada organização do campo de forma individual e coletiva - para realizar campanhas de desmistificação e ressignificação da própria ideia de direitos humanos, disputando os significados associados a esse conceito.

\subsection{Ações de contato e comunicação}

A segunda recomendação aprofunda uma sugestão esboçada no ponto anterior: intensificar as ações de comunicação focadas nas organizações do campo. Isso vem de um dos principais achados da pesquisa: a maior parte dos potenciais doadores de alta renda relata desconhecer organizações de defesa de direitos humanos.

As estratégias de comunicação merecem atenção, levando em conta principalmente duas premissas: a dualidade entre conveniência e confiança. O público pesquisado desconfia de meios tradicionais de abordagem, prezando pela conveniência, mas exige confiança como um pressuposto básico para motivá-lo à doação. Um promissor caminho para equilibrar esses dois requisitos é fazer uso de ações que envolvam pessoas conhecidas e próximas. Indicações de colegas, familiares e amigos tendem a ser muito mais bem recebidas, valendo-se da força dos laços fortes e emprestando a confiança que depositamos em conhecidos para as organizações em busca de recursos.

Cabe lembrar também do promissor papel dos mais jovens como público dessas ações. Dado que o potencial doador de alta renda é tipicamente alguém de meia idade, há bastante potencial para abordagens que envolvam seus filhos como porta de entrada à discussão familiar sobre solidariedade e doações.

Finalmente, sugerimos o desenvolvimento de iniciativas para que atuais doadores de alta renda se tornem "embaixadores" da organização junto a seus familiares e colegas de seus meios sociais e profissionais, novamente reforçando o potencial dos laços em rede. 


\subsection{Demonstração do impacto}

Dentre os requisitos para se engajar com uma ação solidária, à confiança se soma a promessa de impacto: o doador de alta renda quer ter a sensação de que sua ação faz alguma diferença concreta no mundo. Isso leva à necessidade de estratégias de comunicação e mobilização de recursos atentas a narrativas de impacto, demonstrando claramente a transformação na vida de pessoas como resultado da ação da organização. Isso implica em um deslocamento da ênfase em resultados abstratos-quantitativos para resultados particulares-qualitativos.

\section{0 uso de narrativas}

individuais não deve ser deixado de lado, posto que ajuda a dar concretude ao potencial público doador do tipo de impacto que a ação da organização pode ter
Sabemos que muitos dos temas do campo de direitos humanos estão imersos em realidades complexas, de mudanças lentas, conquistas parciais (sujeitas a retrocessos) e luta constante (inclusive com preconceitos e imagens negativas no imaginário popular ou midiático). É importante, claro, tratar dessa complexidade, trazer dados, contextualização, comparações históricas. No entanto, sugerimos que o uso de narrativas individuais não deve ser deixado de lado, posto que ajuda a dar concretude ao potencial público doador do tipo de impacto que a ação da organização pode ter.

\subsection{Flexibilização da doação}

Os dados da pesquisa mostram considerável variedade de perfis e preferências de potenciais doadores de alta renda. Alguns se planejam e buscam forte engajamento; outros são mais desorganizados e reativos. A maioria resiste a abordagens diretas e insistentes feitas por desconhecidos, preferindo comunicações mais impessoais (ou pessoais, desde que vindas de conhecidos). Há também variedade nas formas de concretizar as doações, com uma preferência por meios eletrônicos de pagamento.

Dadas tantas variáveis, a principal sugestão é pela flexibilidade de táticas, formas e periodicidade de pedidos de doação. Ao invés de focar apenas em uma solução ou estratégia, optar por diferentes meios de pagamento, ações de comunicação e mobilização de recursos, fazendo uso inteligente de novas tecnologias de informação para garantir maior comodidade ao público desejado. 


\section{REFERÊNCIAS}

ABDAL, Alexandre; ALVES, Mário Aquino; NOGUEIRA, Fernando do Amaral; PINEDA, Andréa; CAMPOS, Pedro Henrique. Relatório do grupo focal da Pesquisa comportamental sobre doadores de alta renda. Mimeo [não circula], 2018.

ABDAL, Alexandre; ALVES, Mário Aquino; NOGUEIRA, Fernando do Amaral; PINEDA, Andréa; CAMPOS, Pedro Henrique; CALIXTO, Guilherme; CAMPOS, Gisele. Pesquisa comportamental sobre doadores de alta renda. São Paulo: Conectas e CEAPG, 2019. Disponível em: https://doadoresaltarenda.conectas.org/assets/files/relatorio.pdf. Acesso em: 04/05/2019.

ALMEIDA, Ronaldo. Roteiro para emprego de grupos focais. In: ABDAL, Alexandre; OLIVEIRA, Maria Carolina Vasconcelos; GHEZZI, Daniela Ribas; Santos Jr., Jaime. Métodos de pesquisa em ciências sociais: bloco qualitativo. São Paulo: Sesc-Cebrap, 2016. Disponível em: https://centrodepesquisaeformacao.sescsp.org.br/uploads/ BibliotecaTable/9c7154528b820891e2a3c20a3a49bca9/322/1507668143662883762.pdf. Acesso em: 23/05/2018.

BABBIE, Earl. Métodos de pesquisa de survey. Belo Horizonte: UFMG, 2003.

BAILEY, Michael. Fundraising in Brazil: the major implications for civil society organisations and international NGOs. Development in Practice, v. 9, n. 1-2, p. 103-116, 1999.

BECKER, Howard. Segredos e truques da pesquisa. Rio de Janeiro: Zahar, 2007.

CAF - Charities Aid Foundation. World Giving Index 2018: a global view of giving trends. United Kingdom: Charities Aid Foundation, 2018. Disponível em: https://www.idis.org.br/wp-content/uploads/2018/11/WGI2018_REPORT.pdf. Acesso em: 03/04/2019.

DAMATTA, Roberto. Carnavais, malandros e heróis: para uma sociologia do dilema brasileiro. Rio de Janeiro: Rocco, 1997.

FREYRE, Gilberto. Casa grande e senzala. São Paulo: Global, 2006.

HOLANDA, Sérgio Buarque de. Raízes do Brasil. Brasília: Universidade de Brasília, 1963.

IDIS. Pesquisa Doação Brasil 2015. São Paulo: Instituto para o Desenvolvimento do Investimento Social, 2016. Disponível em: https://idis.org.br/pesquisadoacaobrasil/wp-content/uploads/2016/10/PBD_IDIS_Sumario_2016.pdf. Acesso em: 26/03/2018.

MENDONÇA, Patrícia; ALVES, Mário Aquino; NOGUEIRA, Fernando. Civil society organisations and the fight for rights in Brazil: analysis of an evolving context and future challenges. Development in Practice (print), v. 26, p. 592-605, 2016.

MENDONÇA, Patrícia; ALVES, Mário Aquino; NOGUEIRA, Fernando (orgs.). Arquitetura institucional de apoio às organizações da sociedade civil no Brasil. São Paulo: Programa Gestão Pública e Cidadania, 2013.

PRADO Jr., Caio. Formação do Brasil contemporâneo. São Paulo: Brasiliense, 1969.

SCEGO, Igiaba. Minha casa é onde estou. São Paulo: Nós, 2018.

VIANNA, Oliveira. Instituições políticas brasileiras. São Paulo: EDUSP, 1987. 
OS AUTORES

\section{Fernando do Amaral Nogueira fernando.nogueira@fgv.br}

Fernando Nogueira é professor e pesquisador na Escola de Administração de Empresas de São Paulo da Fundação Getulio Vargas (FGV EAESP). É Administrador de Empresas, Mestre e Doutor em Administração Pública e Governo pela mesma instituição. Atualmente é também coordenador do Mobilab+, laboratório de inovação aberta da cidade de São Paulo, vinculado à Secretaria Municipal de Inovação e Tecnologia e à Prodam. Tem como principais tópicos de pesquisa a gestão de associações sem fins lucrativos, a sustentabilidade das organizações da sociedade civil, o investimento social privado, a inovação pública e a descontinuidade de políticas públicas.

\section{Alexandre Abdal alexandre.abdal@fgv.br}

Sociólogo pela Faculdade de Filosofia, Letras e Ciências Humanas da Universidade de São Paulo (FFLCH/ USP) e professor do Departamento de Gestão Pública (GEP) da FGV EAESP, pesquisador do Centro Brasileiro de Análise e Planejamento (Cebrap) e pesquisador vinculado ao núcleo São Paulo da Rede de Pesquisa INCT Observatório das Metrópoles.

\section{Pedro Henrique Campos \\ ph.lopescampos@gmail.com}

Formado em Relações Internacionais pela Universidade de São Paulo (IRI/ USP), assistente de pesquisa no Centro de Estudos em Administração Pública e Governo da Fundação Getulio Vargas (CEAPG), membro do Conselho Editorial da Revista Parlamento e Sociedade e técnico administrativo da Escola do Parlamento Paulistano.

\section{artigos




\title{
artigos GIFE
}

Supervisão: José Marcelo Zacchi e Gustavo Bernardino

Coordenação: Graziela Santiago

Produção editorial: Gleice Regina Guerra

Apoio: Carolina Magosso

Diagramação: Clarissa Sitó

Impressão: Forma Certa

ISSN: 2674-8061

DOI: doi.org/10.33816/gife.20190102a2

(C) 2019 GIFE - Grupo de Institutos Fundações e Empresas

\section{(c) (P) 8}

Este material é disponibilizado sob a licenca Creative Commons Atribuição Não Comercial 4.0 Internacional. http://creativecommons.org/licenses/by-nc/4.0

As opiniões e análises expressas nesta publicação não necessariamente refletem as do GIFE.

\author{
Apoio institucional \\ Fundação Lemann \\ Instituto C\&A \\ Instituto Unibanco
}

\section{QGIFE}

